\title{
Editorial
}

\section{ARTES, TECNOLOGIAS DIGITAIS E O ENSINO EM TEMPOS DE ISOLAMENTO SOCIAL}

Primeiro de janeiro de 2021, Brasil, votos se renovam em milhares de mentes, mensagens eletrônicas de áudio, vídeo ou texto que o novo ano traga melhores notícias, experiências de vida compartilhada por cores, toques de pele, sorrisos ao vivo, gargalhadas sonoras, abraços apertados e muitos sentados em torno da mesa. Ninguém deseja que as dores, dúvidas, angústias e receios que tanto marcaram o ano que findou ontem às 23 h59 se repitam. Porém, certamente, não é apenas acordar de um pesadelo e voltar aos dias festivos e leves do carnaval de 2019, quando o vírus aterrorizando a Europa, depois de cantar sonetos fúnebres na Ásia, parecia que nunca chegaria ao Brasil.

Sobrevivemos, por isso podemos estar aqui lendo essas linhas. Porém milhões de pessoas partiram, outras amargam sequelas e dentre elas, milhares de jovens, adolescentes e crianças tiveram afetado seu ano letivo, senão, drasticamente, outras dimensões de suas vidas.

De acordo com o World Bank (2020), há uma recessão econômica mais profunda do que as crises financeiras mundiais precedentes (2008-2009 e a crise da dívida da América Latina nos anos 1980). A pandemia que começou como um problema da China, alastrou rapidamente a incerteza sobre o cenário econômico com investimentos e o consumo de bens e serviços postergados ou cancelados, abalando mesmo as perspectivas mais promissoras de crescimento para a $3^{a}$ década do século XXI. A redução do comércio com o isolamento social provocou redução da produção industrial, dos serviços de logística, distribuição e afins, o que impactou na redução da jornada de trabalho, demissão de trabalhadores, aumento de falências e retração da oferta de crédito pelo setor bancário, devido à ampliação do risco do investimento (MINISTÉRIO DA ECONOMIA, 2020). Enquanto conglomerados econômicos investiram fortemente na reorganização de seus sistemas produtivos e de comercialização para incrementarem suas finanças diante do novo cenário consumidor, as micro e pequenas empresas (MPE), as quais correspondem $52 \%$ dos empregos formais do setor privado e 99\% do setor empresarial brasileiro (SERVIÇO BRASILEIRO DE APOIO ÀS MICRO E PEQUENAS - SEBRAE, 2020a) viram-se obrigadas a fechar suas portas ou recuperar a velha e boa cooperação familiar para sobreviverem.

No Brasil os recursos destinados ao combate da pandemia são cerca de $5,55 \%$ do PIB do país, sendo semelhante aos pacotes adotados em várias economias desenvolvidas, contudo atreladas a territórios e populações com dimensões bem menores 
que as brasileiras (SILVA; SILVA, 2020). O mesmo governo que fez investimentos tão escassos, assevera por suas agências especializadas que "haverá crescimento na informalidade dos empregos, ampliação da pobreza e desigualdade de renda, o que poderia reacender a onda de protestos sociais" (AGÊNCIA BRASIL, 2020b). Especialistas, por sua vez, lembram que "a superação do coronavírus e a manutenção da economia devem ser entendidas como questões complementares e diretamente relacionadas e não antagônicas" (INSTITUTO DE ECONOMIA DA UFRJ-IE, 2020).

Entre centenas de estudos e artigos publicados abordando a realidade no contexto da pandemia atual, alguns se dedicam a pensar pelo viés da educação a questão. Afinal, cerca de 1.5 bilhões de estudantes ficaram fora da escola em mais de 160 países, em 2020, segundo relatório do Banco Mundial. Diferentes países adotaram o fechamento total de escolas, outros apenas em regiões consideradas de risco ou deixaram abertas as instituições destinadas às crianças pequenas, cujos pais trabalham em setores essenciais: saúde, segurança pública, entre outros. No Brasil, nem para as crianças destes trabalhadores as instâncias governamentais deram atenção. No momento de retomada de alto índice de contaminação, prestes a concluir o ano, decretos governamentais autorizam abertura de escolas sem difundir qualquer critério ou planos de contingências e suporte de ampla aplicação.

Vários organismos mundiais estão publicando estudos sobre as experiências internacionais de medidas para conter a pandemia e seu efeito na educação, enquanto, em nosso país, pesquisadores dedicados empenham-se em equacionar efeitos e soluções do ensino, da aprendizagem e da educação diante da pandemia, como os autores deste número.

Uma dessas iniciativas produzida pelo ensino universitário brasileiro com parceiros importantes é a realizada pelo Instituto Interdisciplinaridade e Evidências no Debate Educacional (IEDE), junto com o Comitê Técnico da Educação do Instituto Rui Barbosa (CTE-IRB) e, tendo o apoio de 26 Tribunais de Contas brasileiros. A equipe organizou uma pesquisa que fez mapeamento das ações das redes públicas de ensino do País durante a pandemia e identificou o planejamento que estavam fazendo, no começo do segundo semestre, para o retorno às aulas presenciais (portaliede.com.br, 2020). Os dados levantados e computados no relatório evidenciam as disparidades regionais e, acima de tudo, como a educação brasileira carece de atenção, investimento e efetivamente de uma política pública adequada. As soluções ao estilo gambiarra foram implantadas com aval de secretarias de educação, como o uso pessoal de contas de redes sociais e telefônicas para viabilizar as aulas remotas, aceitas sem pestanejar como aptas na substituição das aulas presenciais, a despeito da falta de equipamentos, suportes eletrônicos e preparo didático para tal. A antiga noção calhorda de educação prevaleceu: "faz de conta que há ensino, que eu faço de conta que a lição foi aprendida". Conivência de um governo que aprova fundo eleitoral e pouco se importa como um professor, mal remunerado, sem descanso ou suporte poderia improvisar, no interior de sua moradia, as dezenas de salas de aula pelas quais passa, semanalmente, em busca de sua sobrevivência como humano e como educador.

O isolamento social que se impôs tem nos desafiado a pensar sobre as práticas 
de ensino das Artes Visuais, sobretudo refletir sobre o que constitui esse ensino que não acontece somente nos meios institucionalizados, mas também em espaços informais, em espaços onde é possível estabelecer relações de ensino e aprendizagem. Refletindo sobre essas questões vêm em mente algumas memórias de práticas que estiveram presentes no percurso de formação pelas Artes Visuais. São imagens de vivências em oficinas, cursos de extensão, rodas de conversa, exposições e aulas no curso de graduação em artes.

Dessas vivências o que emerge com intensidade é a expansão do espaço e as trocas coletivas. Fora do espaço limitado de uma sala percorria-se pelos ambientes já conhecidos, mas de uma forma diferente. Percebia-se e se registrava a arquitetura, a natureza e as pessoas acionando todos os sentidos do corpo. Dessa forma, percebiam-se os sons, cheiros, formas e texturas. As experiências individuais desse andarilhar por espaços conhecidos se complementavam na coletividade, onde diferentes afetos nos atravessavam. As conversas dos intervalos de aula, os debates de uma leitura, o desenvolvimento de algum projeto e também os abraços configuravam processos de troca e de partilha.

A presença dessas imagens ressalta aspectos intrínsecos ao ensino de artes, elas dizem respeito à sensibilidade e ao aguçamento de uma percepção sensível. Dizem respeito às experiências estéticas e poéticas que não se limitam às práticas de reprodução, domínio de técnicas ou ainda a centralidade em uma produção perfeita e acabada. Assim, percebe-se que um dos desafios do ensino nos dias atuais tem sido pensar como manter esses aspectos da sensibilidade, da estética, das experiências e do coletivo por meio da tecnologia ou ainda, como que o ensino de artes e a produção artística têm percebido esses espaços virtuais onde a corporeidade, a forma como somos afetados e as experimentações são diferentes, nos exigindo vivenciar de outros modos.

O ano de 2020 foi marcado por grandes desafios. Com a pandemia de covid-19, todos tiveram que se reinventar - e o campo das artes não escapou dessa mudança. Editais suspensos, trabalhos coletivos adiados, o meio artístico extremamente abalado; a resiliência foi característica obrigatória. O que foi empecilho ao impossibilitar exposições presenciais, por exemplo, tornou-se oportunidade para que a produção artística alcançasse outros lugares e circuitos. Através da tecnologia e das mídias digitais, exposições virtuais foram feitas e visitadas, lives com artistas contemporâneos discutindo o rumo das artes com abrangência internacional. Simpósios virtuais e publicações de Instagram estimularam o crescimento e a valorização do campo das artes. Artistas aproximaram-se mais do público, compartilhando com todos os seus processos, desejos e anseios. $O$ isolamento social mudou a forma como nos relacionamos e ajudou a valorizar o papel da arte percebida, enfim, como essencial para existir e resistir em tempos adversos. Em meio a manualidades e atenção às faturas estéticas, a saúde mental de milhares foi preservada.

Tocadas por essa pungente realidade que o dossiê n. 29 da revista Palíndromo conta com as reflexões de Patrícia Weissman da Argentina, Virginie Ruppin da França, Francisco Javier Buendia da Colombia, Myriam Lemonchois do Canadá, Maristani Zamperetti da UFPel, ao lado dos artistas Susano Correia e Carlos Alberto Donaduzzi 
que, inclusive, nos presenteia com a sua obra na composição da capa do número. Cada um, à partir de sua realidade e percursos de pesquisa nos convida a pensar em realidades distantes e próximas, afetadas pela atual pandemia e pelos desafios de incorporar a tecnologia em nossos processos de ensino e aprendizagem, de contemplação e experiência estética sem que isso reduza nossa condição de humanos.

Completando o número 29 do 13 ano da Revista Palíndromo temos o prazer de publicar mais sete artigos que trazem em seu temário o corpo e suas relações com a imagem e também com categorias tão necessárias de debates. Artistas e pensadores são colocados em meios às discussões provocadas nestes artigos, como Merleau-Ponty, Ana Mendieta, Oriana Duarte e Richard Long. Dentre os ensaios visuais Renata Voss Chagas e Guilherme Radi Dias propõem um olhar atento para o cotidiano e sua pulsão.

Fechando o número, associado ao dossiê, duas entrevistas produzidas com exclusividade coroam as reflexões que desejamos incitar ao leitor, isolado, mas sedento de luz, de atravessamentos e questões que mantenham viva a vontade, sempre produtiva, de ver o mundo por outros ângulos, sensivelmente, além das normas e imposições, tal como a arte tem o ensejo de proporcionar àqueles que a buscam.

Mara Rúbia ${ }^{1}$ Elisa $^{2}$ e Tatiane ${ }^{3}$

\footnotetext{
1 Doutora em História. Professora efetiva CEART/ PPGAV/UDESC. Editora do Dossiê. E-mail: mara.santanna@udesc.br. Lattes: http://lattes.cnpq.

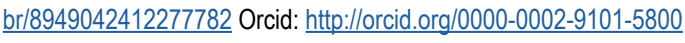

${ }^{2}$ Mestranda em Artes Visuais no PPGAV/UDESC. Editora de Apoio. E-mail: elisavq@gmail.com Lattes: http://lattes.cnpq.br/2956774690632370 Orcid: https:/l orcid.org/0000-0001-6854-4424

${ }^{3}$ Doutoranda em Artes Visuais no PPGAV/UDESC. Editora de Apoio. E-mail: tatirebelatto@hotmail.com. Lattes: http://lattes.cnpq.br/1171169963129518 Orcid: https://orcid.org/0000-0002-9654-8550
} 


\section{Referências:}

SILVA, Mygre Lopes da; SILVA, Rodrigo Abbade da. Economia brasileira pré, durante e pós-pandemia do covid-19: impactos e reflexões. Grupo 7. Observatório Socioeconômico do Covid-19. Universidade Federal de Santa Maria. FAPERGS.

Disponível em: https://www.ufsm.br/app/uploads/sites/820/2020/06/Textos-para-Discuss\%C3\%A3o-07-Economia-Brasileira-Pr\%C3\%A9-Durante-e-P\%C3\%B3s-Pandemia.pdf. Acesso em: 07/12/2020.

SILVEIRA, Lectícia Maggi (org.). A educação não pode esperar. Projeto Ações para minimizar os impactos negativos à educação em razão das ações de enfrentamento ao novo coronavírus. Disponível em: https://www.portaliede.com.br/wp-content/ uploads/2020/06/Estudo_A_Educa\%C3\%A7\%C3\%A30_N\%C3\%A30_Pode_Esperar. pdf. Acesso em 07/12/2020.

INSTITUTO DE ECONOMIA DA UFRJ-IE. Coronavírus: pesquisadores da UFRJ avaliam impacto econômico da doença. Disponível em: https://conexao.ufrj.br/2020/03/18/ coronavirus-pesquisadores-da-ufrj-avaliam-impacto-economico-da-doencal Acesso em: 07/12/ 2020.

THE WORLD BANK. Perspectivas econômicas globais. Disponível em: https://www. worldbank.org/pt/publication/global-economic-prospects. Acesso em 07/12/2020. 